This is a PDF file of an unedited manuscript that has been accepted for publication in Intelligent Decision Technologies. The manuscript will undergo copyediting, typesetting, and review of the resulting proof before it is published in its final form. Please note that during the production process errors may be discovered which could affect the content, and all legal disclaimers that apply to the journal pertain. The final version will be available at: http://dx.doi.org/10.3233/IDT-2012-0141

\title{
Dealing with uncertainty in Decision Support Systems: Recent trends (2000-2011)
}

\author{
Luis C. Dias ${ }^{1,2}$, Carlos Henggeler Antunes ${ }^{2,3}$, David Rios Insua ${ }^{4}$ \\ ${ }^{1}$ Faculty of Economics, University of Coimbra, Av Dias da Silva 165, 3004-512 Coimbra, \\ Portugal \\ 2 INESC Coimbra, Rua Antero de Quental 199, 3000-033 Coimbra, Portugal \\ ${ }^{3}$ Dept. of Electrical Engineering and Computers, University of Coimbra, Pólo II, 3030-290 \\ Coimbra, Portugal \\ ${ }^{4}$ Royal Academy of Sciences, Valverde 22, 28004 Madrid, Spain
}

\begin{abstract}
This paper reviews research in relation with modelling uncertainty within Decision Support Systems (DSS) from 2000 to 2011. It specifically addresses software that has been built or prototyped with the purpose of supporting actual decision making, which is able to explicitly deal with uncertainty (widely understood) on the corresponding model parameters and/or data. The main DSS features analysed are the underlying decision support methodology, the type of uncertainty modelling approach used, the DSS type, and the application area. We appreciate that there is an increasing interest in dealing with uncertainty in real decision support, with prevailing interest in probabilistic approaches and, when linguistic imprecision is involved, fuzzy approaches. We have also recognized an increasing variety of perspectives adopted.
\end{abstract}

\section{Introduction}

This paper reviews a set of recent Decision Support Systems (DSS) that were built to deal with decision making problems in which uncertainty, understood in a broad sense, is a major concern. Decision aiding based on DSS requires the input of data (economic, engineering, geographical, etc.) that can be difficult to obtain for a number of reasons: some data can be missing (e.g., from databases or time series); other data may refer to unknown future outcomes (e.g., future oil prices); other data may be subject to variability according to a 
statistical distribution to be estimated (e.g., the number of nonconforming items in a production batch); other data are known to be subject to physical or statistical measurement error (e.g., the quantity of oil in a well, or the Gross Domestic Product of a country); other data are controversial or contradictory (e.g. data from clinical trials).

In many cases, there are also modelling choices and parameters to be set that involve the subjective judgment of Decision Makers (DMs). For instance, the decision on how to measure comfort or how to assess a company's performance to encompass also environmental or social aspects is, to some extent, arbitrary and subjective. Prior distributions model expert judgements within a Bayesian setting. Many models incorporate parameters related with the DM's preferences, such as those that define how important each criterion is in a multi-criteria evaluation. In purely cognitive terms, some parameters are artefacts whose semantics may be difficult to understand for the DM, and there are well-documented biases related with the way judgmental questions are posed, e.g., (Schoemaker \& Waid 1982). If the DSS is supporting a group decision or negotiation process, it must cope also with the potential lack of consensus as the opinions and preferences of the DMs about parameter values and data may differ. Note that our categorization of nature and sources of uncertainty largely follows that of (Morgan \& Henrion 1990), who provide a detailed discussion.

It is not easy to define a set of keywords able to encompass all types of uncertainty mentioned in the previous paragraphs. This paper used as keywords the logical expression ("dss" $O R$ "decision support system") AND ("uncertainty" OR "robustness") for a search in the SCOPUS bibliographic database. Results were limited to papers published from 2000 to 2011 in a group of 50 journals (Table 1), mostly from the areas of Computer Science and Operations Research. This search was complemented with another one focusing on the Intelligent Decision Technologies journal, as it is not yet indexed in this database, as well as a few other papers the authors were aware of. This resulted in a set of over 300 papers, which was then reduced to meet a number of a priori defined criteria for inclusion in this review.

The first criterion was that the paper should describe a DSS in the form of a well-defined software implementation, either fully deployed or as a working prototype, usually having a name given by its authors. This included not only standalone applications, but also software modules that run on other platforms, such as add-ons or plug-ins. Therefore, we have not included papers that are of a philosophical nature, or just presenting a framework or method. The same applies to papers that present algorithms implementing a method just to perform computational experiments, or comparisons with other methods, or to obtain results for an illustrative example. We neither include papers with the mere purpose of providing suggestions or guidelines for DSS development, or that discuss projects not yet implemented. Finally, papers presenting surveys or comparative studies of previously published systems are not included either.

A second criterion for inclusion in this review was that the DSS would require human intervention in the actual decision making process. This excluded papers about systems supposed to work without, or with very little, human intervention, such as industrial control systems, intelligent agents, or autonomous vehicles and robots. Systems that fundamentally 
aim at knowledge discovery, such as pattern recognition, information fusion, data mining, and diagnosis tools were also considered out of the scope for our review.

Finally, we sought to include only DSS that explicitly deal with uncertainty models for decision making. This left out several papers concerning neural networks and expert systems without any explicit modelling of uncertainty. Other excluded papers used an indicator to measure risk or uncertainty as a function of deterministic characteristics (e.g., considering a risk criterion in a multi-criteria evaluation).

Note that, by and large, we conform to the DSS definition in (French et al. 2009, p. 83), that is a "computer-based systems that support the decision-making process, helping DMs to understand the problem before them and to form and explore the implication of their judgements, and hence to make a decision based upon understanding" and, more specifically, to what are called level 2 and 3 DSS there, thus focusing on actual decision support.

Table 1. Number of selected papers per journal (total $=83$ )

\begin{tabular}{|c|c|}
\hline Journal & $\begin{array}{l}\text { No. of } \\
\text { papers }\end{array}$ \\
\hline Expert Systems with Applications & 15 \\
\hline Decision Support Systems & 12 \\
\hline Environmental Modelling and Software & 7 \\
\hline $\begin{array}{l}\text { J. of the Operational Research Society, Knowledge Based Systems, Intelligent Decision } \\
\text { Technologies }\end{array}$ & 4 \\
\hline $\begin{array}{l}\text { Computers and Electronics in Agriculture, Int. J. of Computational Intelligence Systems, } \\
\text { Int. J. of Production Economics }\end{array}$ & 3 \\
\hline $\begin{array}{l}\text { Advanced Engineering Informatics, Annals of Operations Research, Computers and } \\
\text { Operations Research, Engineering Applications of Artificial Intelligence, Fuzzy Sets and } \\
\text { Systems, Int. J. of Geographical Information Science , Omega }\end{array}$ & 2 \\
\hline $\begin{array}{l}\text { Applied Mathematics and Computation, Artificial Intelligence in Medicine, European J. } \\
\text { of Operational Research, Expert Systems, Int. J. of Decision Support System } \\
\text { Technology, Interfaces, Journal of Multi-Criteria Decision Analysis, J. of Optimization } \\
\text { Theory and Applications, Medical Decision Making, Military Operations Research, } \\
\text { Operations Research, Stochastic Environmental Research and Risk Assessment, } \\
\text { Technological Forecasting and Social Change, Trans. in GIS }\end{array}$ & 1 \\
\hline $\begin{array}{l}\text { Applied Soft Computing J., Cochrane Database of Systematic Reviews Online, Computer } \\
\text { Methods and Programs in Biomedicine, Computers and Industrial Engineering, IEEE } \\
\text { Trans. on Neural Networks, IEEE Trans. on Systems Man and Cybernetics (Part A, Part } \\
\text { B, Part C), Infor J., Information Systems Frontiers, Int. J. of Approximate Reasoning, Int. } \\
\text { J. of Computer Applications in Technology, Int. J. of Computers Communications and } \\
\text { Control, Int. J. of Management and Decision Making, Int. J. of Production Research, } \\
\text { Lecture Notes in Computer Science (including Subseries Lecture Notes in Artificial } \\
\text { Intelligence and Lecture Notes in Bioinformatics), Optimization Methods and Software, } \\
\text { Reliability Engineering and System Safety, Risk Analysis, Studies in Computational } \\
\text { Intelligence, Transp. Planning and Technology, Transp. Research (Part A, Part C), } \\
\text { Transp. Research Record }\end{array}$ & 0 \\
\hline
\end{tabular}

Even with our possibly narrow notions of DSS and uncertainty models, 83 papers still remained in our review, with the journal distribution presented in Table 1. As would be expected, the 
two journals with higher number of papers are devoted to decision support technologies, but surprisingly the third journal with more papers is devoted to applications in the environmental area. According to Figure 1, the number of papers is comparatively low but has a clear increasing trend, suggesting an increasing interest in this topic. The complete list of papers is presented in Table 2.

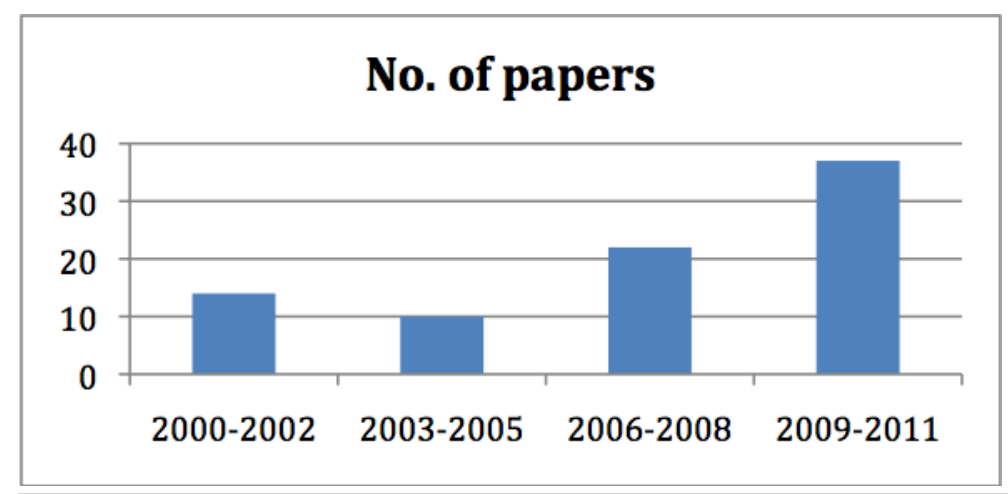

Figure 1. Evolution of published DSS papers dealing with uncertainty and robustness 


\section{Table 2. List of papers considered in this revision}

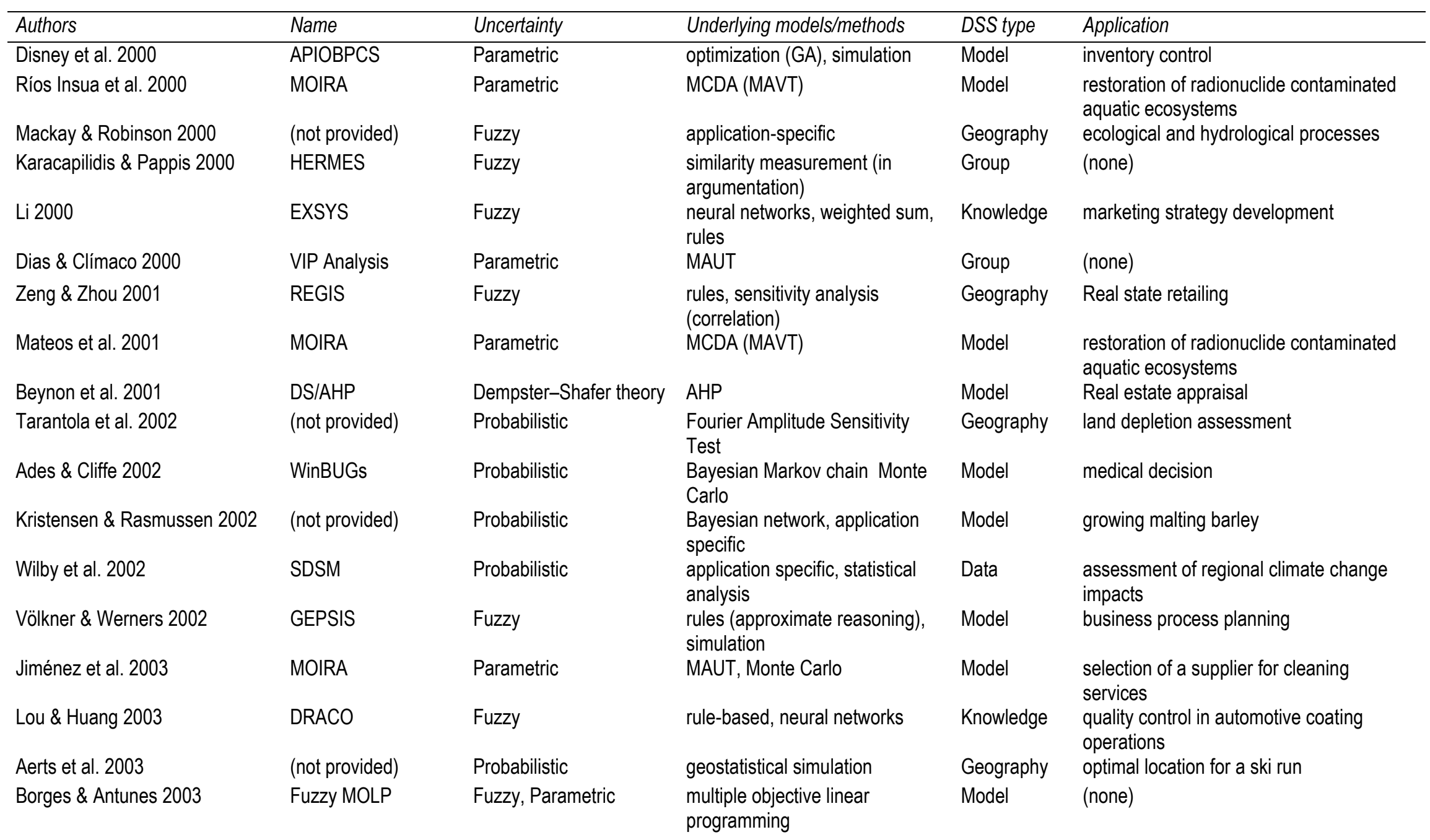




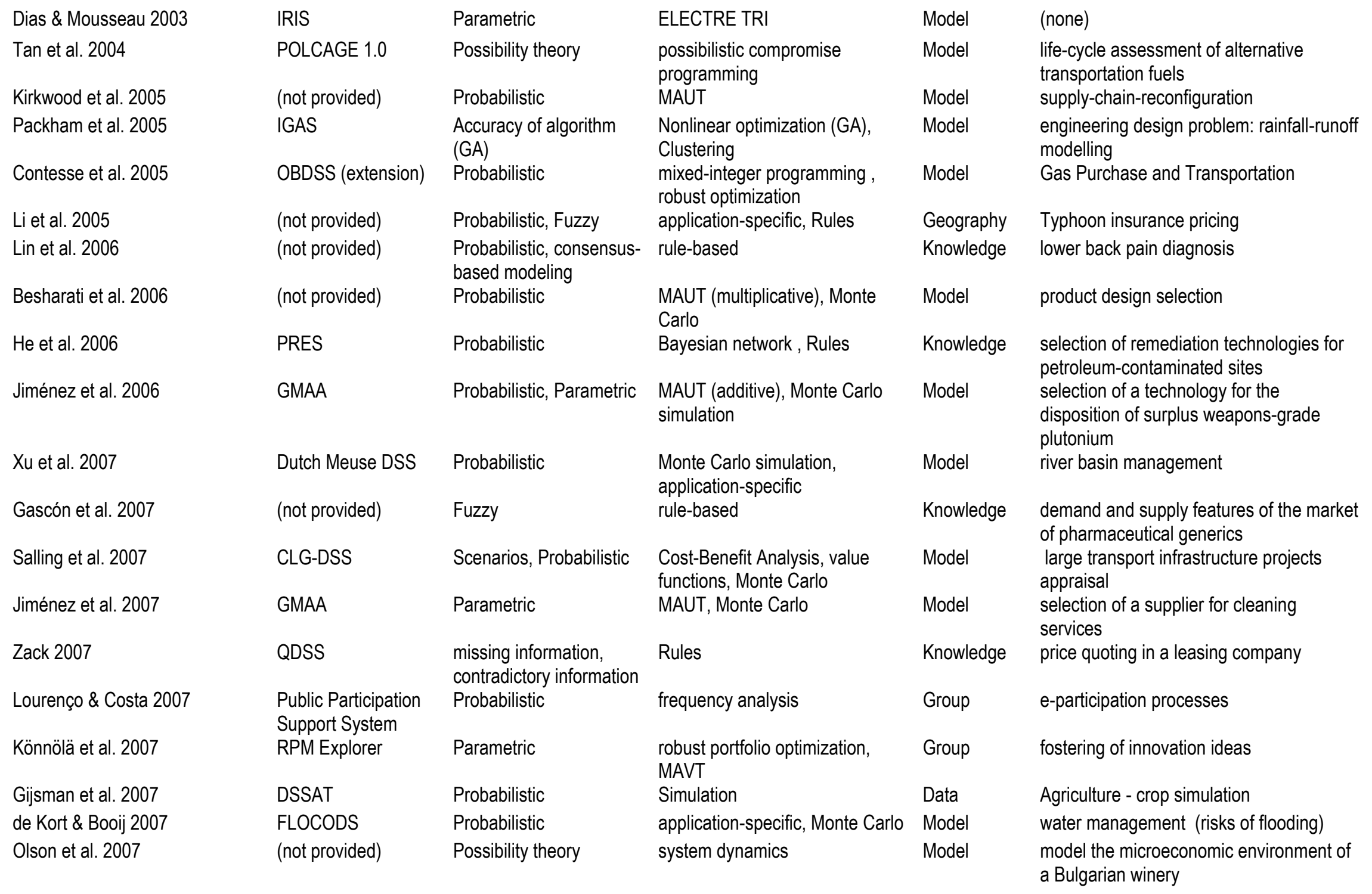




\begin{tabular}{|c|c|c|c|c|c|}
\hline Augusto et al. 2008 & RIMER & Evidential Reasoning & rule-based & Knowledge & monitoring and diagnosis in a smart home \\
\hline Castelletti et al. 2008 & (not provided) & Probabilistic & $\begin{array}{l}\text { Stochastic optimal control, Multi- } \\
\text { objective optimization }\end{array}$ & Model & water resources planning \\
\hline Chin et al. 2008 & (not provided) & Evidential Reasoning & AHP & Model & product project screening \\
\hline Lee \& Kwon 2008 & NSS CAKES-NEGO & Fuzzy & Fuzzy Cognitive Maps (FCMs) & Knowledge & B2B negotiation \\
\hline Gomes et al. 2008 & THOR & Fuzzy & MCDA & Model & Solid waste management \\
\hline Yazg1 Tütüncü et al. 2008 & BEKS & Fuzzy, Probabilistic & $\mathrm{EOQ}$, simulation & Model & inventory control \\
\hline Guitouni et al. 2008 & CASAP & Fuzzy, Probabilistic & MCDA (PAMSSEM) & Group & military planning \\
\hline Lu et al. 2008 & WFGDSS & Fuzzy & $\mathrm{AHP}$ & Group & Critical situation management \\
\hline Kong et al. 2009 & IDS & Evidential Reasoning & rule-base inference & Knowledge & Medicine \\
\hline Saenz de Ugarte et al. 2009 & (not provided) & Real-time contingencies & genetic algorithm, simulation & Data & scheduling \\
\hline Montmain et al. 2009 & SINERGIE & Parametric & MCDA (MAUT) & Model & motorway maintenance \\
\hline Guezguez et al. 2009 & PIDT & Possibility theory & Influence diagrams & Model & (none) \\
\hline Namen et al. 2008 & Robus & Scenarios & Robustness Analysis PSM & Model & sustainable community development \\
\hline Chou 2009 & PILCES & Probabilistic & $\begin{array}{l}\text { Regression, Generalized linear } \\
\text { models, application-specific }\end{array}$ & Model & cost estimation in construction \\
\hline Li \& Li 2009 & (not provided) & Fuzzy, Probabilistic & $\begin{array}{l}\text { AHP, Monte-Carlo, approx. } \\
\text { Reasoning }\end{array}$ & Model & strategic planning \\
\hline Jiménez et al. 2009 & MOIRA & $\begin{array}{l}\text { Probabilistic, missing } \\
\text { data }\end{array}$ & MCDA (MAUT) & Model & $\begin{array}{l}\text { restoration of radionuclide contaminated } \\
\text { aquatic ecosystems }\end{array}$ \\
\hline Cai et al. 2009 & UREM-IDSS & Interval, Scenarios & optimization (LP) & Model & $\begin{array}{l}\text { regional energy management systems } \\
\text { planning }\end{array}$ \\
\hline Clímaco et al. 2009 & D2VIP-A & Parametric & MAUT & Group & (none) \\
\hline Weng et al. 2010 & HWRDS & Scenarios, Fuzzy & $\begin{array}{l}\text { multi-objective programming, } \\
\text { Fuzzy aggregation, AHP }\end{array}$ & Model & water resources management \\
\hline Zhou et al. 2010 & APIOBPCS & Probabilistic & Order-up-To Algorithm & Model & inventory management \\
\hline Louvieris et al. 2010 & (not provided) & Probabilistic & Bayesian belief networks & Model & military \\
\hline Gemici-Ozkan et al. 2010 & (not provided) & Probabilistic & multistage stochastic program & Model & portfolio optimization \\
\hline Zhang et al. 2010 & FMCGDSS & Fuzzy & Fuzzy MCDM aggregation & Model & Power distribution system planning \\
\hline Ma et al. 2010 & Decider & Fuzzy & multi-criteria group decision & Model & (none) \\
\hline $\begin{array}{l}\text { Pereira \& Ramli } 2010 \\
\text { De Maio et al. } 2011\end{array}$ & $\begin{array}{l}\text { ACORDA/P-log } \\
\text { (not provided) }\end{array}$ & $\begin{array}{l}\text { Probabilistic } \\
\text { Fuzzy }\end{array}$ & $\begin{array}{l}\text { Causal Bayes Nets } \\
\text { Fuzzy Cognitive Maps (FCMs) }\end{array}$ & $\begin{array}{l}\text { Knowledge } \\
\text { Web }\end{array}$ & $\begin{array}{l}\text { (none) } \\
\text { Emergency management }\end{array}$ \\
\hline
\end{tabular}




\begin{tabular}{|c|c|c|c|c|c|}
\hline Patiniotakis et al. 2011 & Fuzzy UTASTAR & Fuzzy & UTA & Model & Transportation \\
\hline Papadopoulos et al. 2011 & (not provided) & $\begin{array}{l}\text { Fuzzy, Sensitivity } \\
\text { analysis }\end{array}$ & Rules & Knowledge & agriculture \\
\hline Yang et al. 2010 & IDS & Evidential Reasoning & rule-based functions & Knowledge & marketing \\
\hline Li et al. 2011 & WebDigital & Fuzzy & $\begin{array}{l}\text { Rules if-then, Monte Carlo } \\
\text { simulation }\end{array}$ & Knowledge & digital marketing \\
\hline Mouzakitis et al. 2011 & Axios & Fuzzy & PROMETHEE & Web & investment \\
\hline Qi \& Altinakar 2011 & (not provided) & Probabilistic & $\begin{array}{l}\text { Monte Carlo Simulation, event } \\
\text { tree analysis }\end{array}$ & Geography & flood management \\
\hline Beraldi et al. 2011 & (not provided) & Probabilistic & $\begin{array}{l}\text { Simulation, Stochastic } \\
\text { programming }\end{array}$ & Model & asset allocation \\
\hline Rees et al. 2011 & (not provided) & Fuzzy & Genetic algorithm (optimization) & Model & Cybersecurity risk planning \\
\hline Leu \& Adi 2011 & MDS & Probabilistic & $\begin{array}{l}\text { Hidden Markov Model } \\
\text { autoregressive time series }\end{array}$ & Model & drainage water tunnel \\
\hline Noor-E-Alam et al. 2011 & (not provided) & Fuzzy & ME-MCDM & Model & supplier evaluation \\
\hline Chen et al. 2011 & CEDSS & $\begin{array}{l}\text { Probabilistic, Fuzzy, } \\
\text { Indicator-based }\end{array}$ & $\begin{array}{l}\text { multi-criteria analysis (additive } \\
\text { v.f.) }\end{array}$ & Geography & river catchment management \\
\hline Ting et al. 2011 & HKSMP & Probabilistic & $\begin{array}{l}\text { Bayesian reasoning, case-based } \\
\text { reasoning (CBR) }\end{array}$ & Knowledge & medical prescription \\
\hline Zhang et al. 2011 & FICMDSS & Fuzzy, Interval & inexact programming & Model & $\begin{array}{l}\text { water quality management in agricultural } \\
\text { systems }\end{array}$ \\
\hline Damghani et al. 2011 & (not provided) & Fuzzy & $\begin{array}{l}\text { mathematical programming, } \\
\text { Rules }\end{array}$ & Model & investment selection \\
\hline Wang et al. 2011 & MPVFDSS & Vague sets & application-specific & Model & Wafer manufacturing \\
\hline Kala et al. 2011 & SANE & Probabilistic & neural networks, sum integration & Knowledge & medical diagnosis \\
\hline Papageorgiou 2011 & (not provided) & Fuzzy & $\begin{array}{l}\text { Fuzzy Cognitive Maps (FCMs) } \\
\text { DEMATEL (MCDA) }\end{array}$ & Knowledge & modelling medical knowledge \\
\hline Loboda et al. 2010 & (not provided) & Probabilistic & Bayesian network & Knowledge & $\begin{array}{l}\text { generating real-time suggestions to } \\
\text { improve users performance }\end{array}$ \\
\hline Chen et al. 2011 & CEDSS & Probabilistic & MCDA (MAVT) & Geography & river catchment management \\
\hline
\end{tabular}


We shall analyse the papers reviewed based on four key issues in relation with uncertainty within DSSs: how uncertainty is modelled within the incumbent DSS; what is the underlying decision aiding methodology used that accommodates uncertainty; what type of DSS is actually used from an architectural point of view; and, finally, the application area. Other generic relevant features in DSSs are described in (Burstein \& Holsapple 2008).

\section{Strategies to deal with uncertainty}

In this section, we provide a brief introduction to various types of strategies and models used in the reviewed literature, as far as uncertainty is concerned. The treatment is necessarily brief for space reasons, but we shall provide pointers to the literature where further information may be seen on various approaches. Clearly, several of the strategies employed are intimately related, as outlined below, and indeed may be used in combination. For example, within a probabilistic setting it is convenient to undertake a sensitivity analysis to check the impact of probabilities and utilities on the DSS recommendation, see (Rios Insua \& Ruggeri 2000).

- Probabilities

Probabilities constitute the most widely used and best known formalism for quantifying uncertainty. Probabilities have well-defined mathematical properties based on Kolmogorov's axioms, with various interpretations, including the frequentist and the subjective, the latter being the most general. In this last interpretation, probabilities are described as a measure of the degree of belief in the occurrence of an event, and have behavioural axiomatic foundations. Such foundations lead to a natural way of updating beliefs in the light of new evidence based on Bayes theorem (French \& Rios Insua 2000). Procedures to elicit beliefs are described, e.g., in (O'Hagan et al. 2006).

Complex probability models may be sometimes described through graphical models, of which the most popular ones are Bayesian networks, which are also sometimes called causal networks, belief nets or probabilistic influence diagrams. If the graphical model includes decision and value nodes, they fully describe the decision problem at hand.

Some of the DSSs reviewed incorporate probabilistic elements to standard optimization problems, either on constraints or objective terms, leading to stochastic programming problems, which may be solved with various strategies described, e.g. in (Birge \& Louveaux 2011).

A frequent criticism to the probabilistic approach lays in the difficulty of building the incumbent probability distributions, therefore leading to other uncertainty paradigms.

- Imprecise probabilities

A natural extension of the probability model is the imprecise probability model. The underlying principle is that, normatively, we should build a unique probability 
modelling the DM's beliefs. However this requires ultrafine discerning capabilities on the DM, who may not be able to provide such precise information. It may be also the case that we need to deal with several DMs (precise or not) and imprecise probabilities emerge as a way to model the common knowledge grounds of all participants.

One natural way of thinking about imprecise probabilities is through upper and lower probabilities. For a given event, relevant in the decision problem at hand, we are not able to provide the precise probability, but rather upper and lower bounds for such probability. If this occurs for all relevant events, we have an upper and lower probability model, provided that the bounds satisfy certain coherence requirements. A well-known model of upper and lower probabilities is Dempster-Shafer evidence theory, see (Shafer 1976), which uses belief and necessity measures as bounds. A good overview of these theories may be seen in (Miranda 2008).

We may handle, however, more general constraints on probabilities based on inequality constraints and others, which generally lead to the concept of convex sets of probabilities, which have an axiomatic behavioural support. Clearly, based on the convex set of probabilities, we may define an upper and lower probability model.

The operationalization of this approach faces two problems. The first one refers to the updating of information in the light of new evidence. The natural idea is to consider a class of standard models and update each of them through Bayes' formula. However, this may be difficult to implement except under very stringent structural conditions and we may need to use approximations and simulation, see (Rios Insua \& Ruggeri 2000) for an overview. Some of the paradigms, like Dempster-Shafer's approach which uses Dempster's combination rule, lead to their own updating rules.

The second problem refers to the recommendations to be provided by the DSS. Again, it is natural to view the issue as a class of standard decision problems and solve them individually and either show the whole set of solutions or try to summarise somehow such set of solutions based on their common grounds. By doing this, we are performing some kind of sensitivity analysis. This may be too involved computationally and we may go for computing solutions which are robust in some sense. Typically, these are solutions with a certain guarantee of performing reasonably well under all relevant probability models or which perform reasonably well for a sufficiently large class of probability models. By reasonably well, we refer to a large number of criteria being considered, such as attaining a minimum target expected utility or minimizing the entailed regret (of not being the actual best alternative).

Note that we have focused this discussion on the belief part of the DSS model, but similar issues may be mentioned about the preference part, i.e. we might have imprecision about preferences, e.g. to be dealt with through classes of utility functions.

Also, some of the methods have been combined to provide somewhat different approaches. For example, utility theory, Dempster-Shafer's theory of evidence, 
statistical tools, and information technology are combined in the so-called evidential reasoning approach, as in (Xu et al. 2006).

- Set inclusion

Several approaches focusing on imprecision (or incompleteness), mainly in preferences, deal in reality only with the sets of values that the parameters of interest (weights of a utility function, probabilities of events, group member weights, etc.) may adopt. The approach in this case is clearly parametric and the ideas outlined above concerning sensitivity analysis are relevant here. These include the undertaking of what-if analysis (e.g., what is the optimal solution if the parametric setting is a given one); the computation of worst outcomes for each alternative to find out the alternative with best worst outcome, as a concept of robust solution; or the computation of the volume of the parametric set under which a given solution is optimal, as a way to ascertain its robustness.

The idea of set inclusion is used as we consider sets of parameters and the smaller the sets, the more precise the information is. Indeed, under the normative ideal, we shall typically have a singleton parametric set, e.g. with the corresponding unique utility function weights. Moreover, several set inclusion based procedures incorporate mechanisms to suggest directions or areas in which the parameter set may be reduced to attain higher robustness and increase the DM's confidence on the results of the analysis. Interval numbers may be included within this heading.

(Vilkkumaa et al., in print) include an overview on approaches in which set inclusion ideas are relevant.

- Scenario development and analysis

Scenario analysis may be contemplated as well within the set inclusion paradigm. It refers mainly to problems of strategic nature and long-term effects, in which we are able to identify relevant events or developments for the future, the so-called scenarios. However, for reasons such as lack of knowledge or too much uncertainty, we are not capable or it does not seem sensible trying to assess the corresponding probabilities. Sometimes these are called problems under severe uncertainty, see e.g. (Wright \& Goodwin 1999). There is a clear resonance of the classical distinction between decision making under risk and under uncertainty, see e.g. (French 1986). Therefore, the standard solutions from decision making under uncertainty have been used in this case, including providing equal weights to various scenarios, minimum regret solutions, as well as variants which try to cater for various degrees of pessimism and risk aversion.

- Linguistic imprecision

Many of the papers reviewed in this area used some kind of fuzzy set based approach. Fuzzy set based concepts were introduced to cope with imprecision in language. Rather than using standard (crisp) sets, in which we may say that an element belongs or not to the set, fuzzy sets are used in which a degree of membership, between 0 and 
1 , is given to each element. Based on such ideas, standard set concepts are fuzzified. Similarly, standard decision support tools and methodologies have been fuzzified, e.g fuzzy cognitive maps, fuzzy aggregation rules or fuzzy MCDM approaches, see (Ross 2010).

Possibility theory was introduced as an extension of fuzzy sets and fuzzy logic by (Zadeh 1978). The key concept is that of a possibility measure which aims at modelling the possibility of an event happening. The distinctive feature of possibility measures is that the possibility of the union of two events is the maximum of the possibility of both events. Possibility theory uses also the necessity of an event, which is one minus the possibility of the complementary set. Recommendations are based on extensions of integral concepts (with respect to possibility measures) like Sugeno's integral.

Interestingly enough, possibility (and necessity) measures may be seen as particular cases of upper and lower probabilities.

Figure 2 provides a frequency distribution of the various approaches used in dealing with uncertainty within DSS. Probabilistic approaches are the most frequent, followed closely by those based on fuzzy concepts, including possibility measures. The other approaches appear much less frequently. Note that probabilistic approaches, followed by fuzzy approaches have prevailed over the years (Figure 3). However, in recent years the variety of uncertainty modelling strategies has increased. 


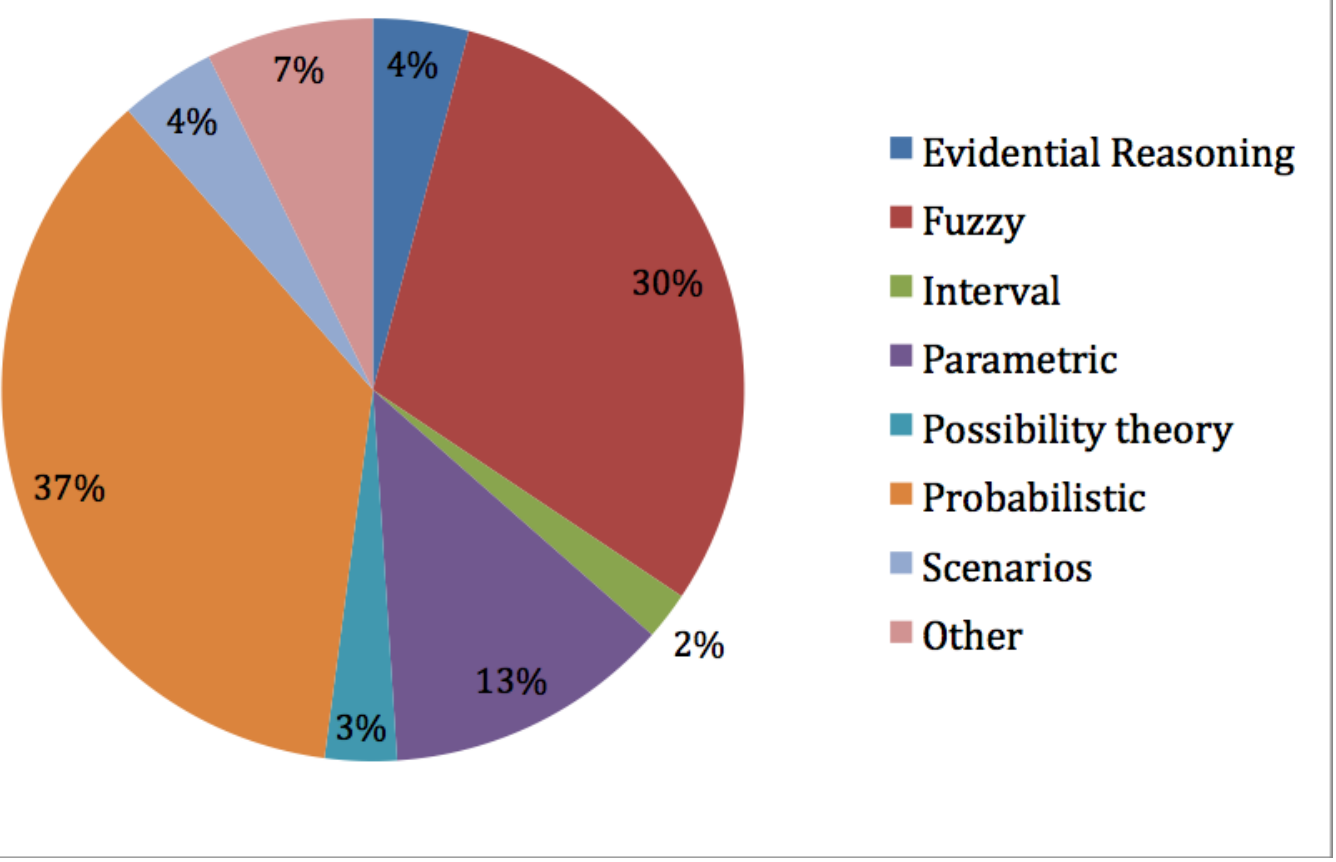

Figure 2. Frequency of different uncertainty modelling strategies in this review.

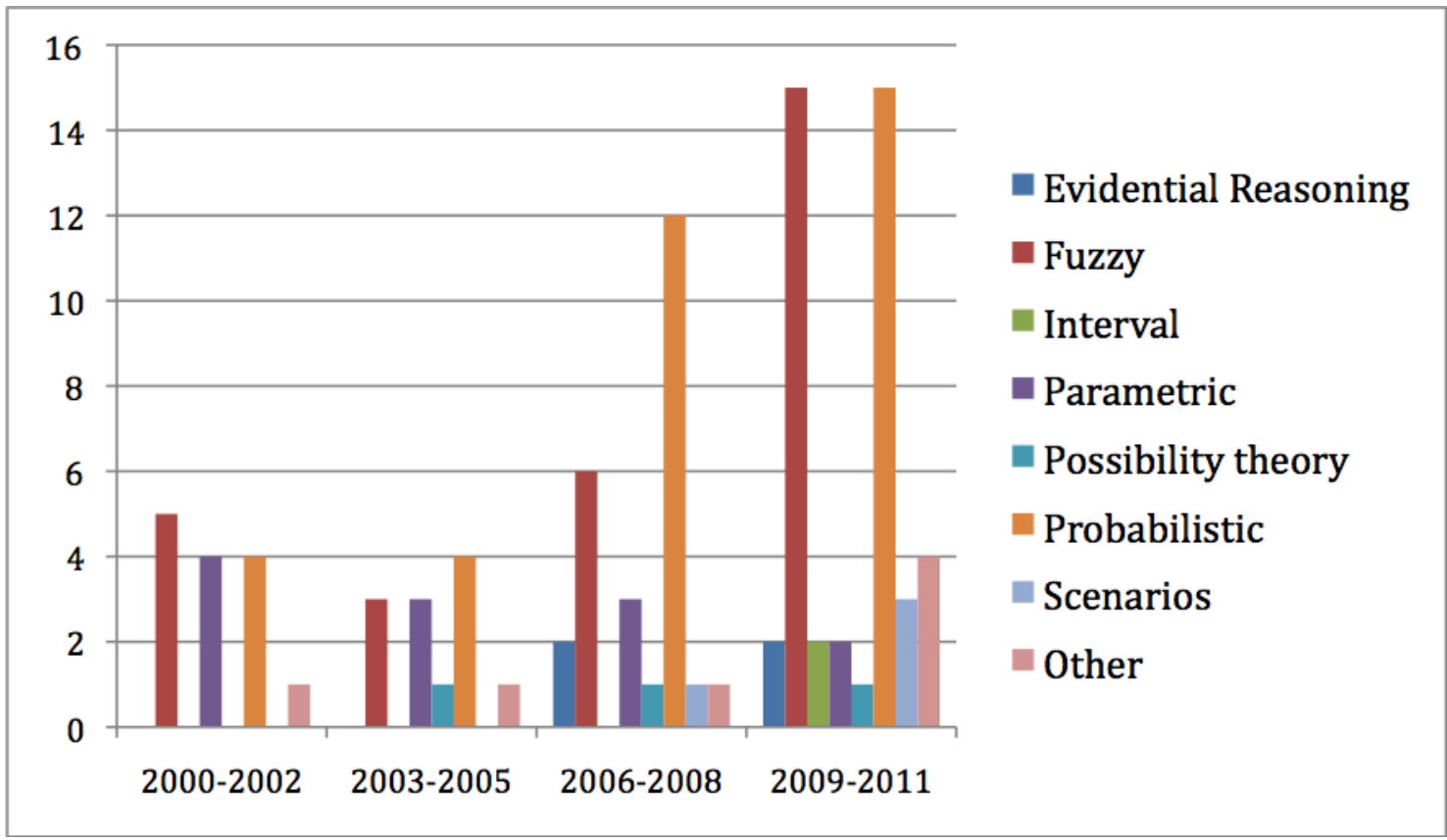

Figure 3. Evolution of strategies to model uncertainty.

\section{Underlying decision support methodology}

Concerning the underlying decision support methodology within which the treatment of uncertainty is considered, we have identified the following categories in this review: optimization, multi-criteria decision analysis (MCDA), rules, simulation, cognitive maps, 
artificial neural networks and Bayesian networks. The main features of these approaches are briefly described below.

- Optimization

Optimization-based DSS generally use an optimization engine for (linear, non-linear, integer) mathematical programming models, which may be built upon a commercial solver or is specifically tailored, for instance, to make the most of special algorithmic features taking advantage of structural properties of the problem at hand. In particular, to deal with complex combinatorial or/and strongly non-linear models meta-heuristics are also used, which may be hybridized with mathematical programming approaches (generally under the designation math-heuristics), such as genetic/evolutionary algorithms, simulated annealing, or tabu search (Gendreau \& Potvin 2010).

One of the most important features required for optimization-based DSS, particularly in dealing with large-scale optimization models, is the capability of problem generation, in general using some kind of algebraic modelling languages. These are high-level programming languages offering a similar syntax to the usual mathematical notation for optimization problems. This permits a clear separation between the model structure, the data to be supplied to the model and the specific solution method. Furthermore, this enables model changes and maintenance to be carried out in a gradual manner over the system lifetime. However, the use of such algebraic modelling languages has not been reported in the set of papers reviewed.

Moreover, due to the intrinsic complexity of optimization models, optimization-based DSS should provide results analysis and reporting capabilities to assist DMs who are knowledgeable regarding the application domain but to whom expertise on mathematical models and algorithms cannot be required.

Techniques to cope explicitly with uncertainty in optimization models include stochastic programming (in which uncertainty is modelled through discrete or continuous probability distributions), fuzzy programming (in which coefficients are modelled through fuzzy numbers, and constraints and objective functions for which a goal is specified are dealt with as fuzzy sets), interval programming (in which the coefficients are interval numbers, that is, they are unknown but bounded with no need to specify probabilistic distributions as in stochastic programming or possibilistic distributions as in fuzzy programming). The establishment of plausible ranges in which model coefficients and parameters may drift is also considered by robust optimization, which seeks to compute solutions compatible with all those values. That is, solution robustness is measured in terms of its best performance against all possible realizations of the coefficients and parameters values. Min-max and min-max regret are usual formulations in the realm of robust programming (Kouvelis \& Yu 1987), in which it is also possible to establish, for instance, a probability for which the solution is required to satisfy specific constraints.

\section{- Multi-criteria / multi-objective models (MCDA)}

A multi-criteria decision support system (MCDSS) is based on multi-criteria models and methods. In general, the label multi-criteria encompasses models in which the set of potential solutions are implicitly defined by a set of constraints (multi-objective) or they are explicitly known a-priori (multi-attribute).

In multi-objective models, the multiple axes of evaluation of potential solutions are operationalized through objective functions to be optimized, usually conflicting and incommensurate, in the feasible region defined by the set of constraints. The aim of the decision process may be characterizing as extensively as possible the non-dominated solution set in order to learn about the underlying trade-offs in different regions of the search space or 
supporting the DM in recognizing a compromise solution providing an acceptable balance between the competing objective functions. This might be accepted as the final outcome.

Uncertainty in multi-objective models usually concerns the coefficients of the objective functions and/or the constraints. It may also concern the decision (control) variables values, e.g. assessing the degrading of the objective function values if the decision variables drift from their optimal values within a certain range. The approaches mentioned for optimization (stochastic programming, fuzzy programming, and interval programming) are also applied for multi-objective models. In this case, instead of evaluating the behaviour of the optimal solution in face of uncertainty, the behaviour of a non-dominated solution (or a sample of the non-dominated solution set or even the entire non-dominated frontier) is assessed.

In multi-attribute models three types of problems are generally considered: choice (selecting the best alternative or a reduced sub-set of alternatives for further screening), sorting (assigning the alternatives to pre-defined ordered categories of merit), or ranking (generating a complete or partial ranking of the alternatives from the best to the worst, possibly accepting ties). Since in these models there is not a prominent solution due to the conflicting nature of the criteria, the involvement of the DM in providing information about his/her preferences is of paramount importance. MCDSS should be designed to help the DM getting a better understanding of complex decision problems, through an interactive process with a constructive framework ranging from problem structuring to shaping the decision model and alternatives.

Uncertainty in multi-attribute models usually concerns the performances of the alternatives on the different criteria and/or the preference-related parameters (e.g., criterion weights). The uncertain performances of the alternatives are usually addressed using scenarios, probability distributions, or fuzzy sets. The difficulties of setting parameter values are usually addressed performing parametric analyses (sensitivity analysis, robustness analysis) of sets of acceptable model versions, scenarios (namely to take into account multiple perspectives), or using linguistic quantifiers.

- Rules

If-then rules are used to structure information with a semantic content about a specific domain, allowing relationships to be defined between the data. Usually, an inference engine combines the rules from the knowledge base with new data to provide a recommendation. This type of DSS is based on rules elicited from human domain experts that imitate reasoning of a human expert in that domain, expectedly at a comparable level. Caution must be taken since imitating human thinking and its efficient heuristic principles, which is well described e.g. in (Gigerenzer et al 1999), may also lead to imitate its flaws. These systems are generally endowed with some explanatory capabilities to justify why a particular recommendation has been given.

The treatment of uncertainty may be made using fuzzy rules, whose membership functions are aimed at capturing, for instance, linguistic variables through statement such as: "if control variable $\mathrm{x}$ is low, then radiation should increase". Bayesian networks, described below, may be viewed as if-then rule-based systems with probabilities.

- Simulation

Simulation generally refers to approaches that replicate computationally the behaviour of an actual or projected human or physical system. Typically in a simulation-based DSS, several simulation runs are executed and their aggregate results lead to recommendations. The decision variables in the model are the inputs that are manipulated in the test.

Simulation-based DSS are mostly used for dynamic analysis of system operations, for predicting and exploring the system behaviour (i.e., assessing the effects of specific events and 
actions). Agent-based simulation has recently gained an increasing importance due to the availability and affordability of computational power, which makes possible to adopt a bottomup system perspective, i.e. focusing on the system components as the essential units (which have very simple behaviour) and complexity gradually emerges as the analysis progresses to upper system levels. Simulation-based DSS are often coupled with visual tools, which enable visual information feedback about the system behaviour.

Uncertainty may be related with information arising from the random behaviour of physical systems (dealt with statistical and probabilistic methods) and from human perception and cognition processes (for which fuzzy logic and neural networks are often used).

Simulation-based DSS have been used to deal with problems in production scheduling, manpower planning, for instance in call-centres, inventory planning and control, queuing systems, designing overbooking policies, hedging against financial risks, etc.

\section{- $\quad$ Cognitive maps}

Cognitive maps display a representation of human thinking about a specific domain, by graphically mapping concepts and their inter-connections, identifying causes and effects, and explaining causal links. Cognitive maps may be used to unveil mental models of DMs, particularly shaped by the ways in which they anticipate events.

Fuzzy cognitive maps have been used to model dynamic systems with uncertain, imprecise and incomplete causal information (Kosko 1992; Glykas 2010). A fuzzy cognitive map is a fuzzy signed oriented graph, in which nodes represent concepts and directed graphs interconnecting nodes represent causal relationships. Each concept has state values, which reflect the degree with which the concept is active at a particular time. The state space of nodes is modelled as a fuzzy set to represent the concept. The weight associated with the directed arc measures the strength of the causal relationship. In general, this weight lies between -1 (strong negative causality between the concepts) to 1 (strong positive causality), while 0 indicates there is no causal relationship. The inference process in fuzzy cognitive maps is an iterative process consisting of updating the state vector values according to a weight matrix and initial conditions, in a discrete time mode. The descriptive approach of standard fuzzy cognitive maps may be complemented with probabilistic information to consider the impacts of randomness (caused by occurrence of random events) besides fuzziness (model of inexactness mostly due to human judgment).

- Artificial neural networks

Artificial neural networks, the analogy of which is emulating the functioning of human brain, consist of neurons - highly distributed interconnected adaptive nonlinear processing units - and synapses - structural and functional units that mediate the interactions between neurons (Kosko 1992). Knowledge is acquired by means of a learning process and synapse weights are used to store it. According to their architecture, neural networks may be classified as non-adaptive (no feedback loop exists), unsupervised (network weights are changed according to some specified set of rules - self-organization) and supervised (an external function provides a measure of the output quality). The hybridization between fuzzy logic and neural networks is generally aimed at capturing cognitive uncertainty, in which the latter are used to design and tune fuzzy membership functions to produce better output decisions. As weights are used in some MCDA methodologies to reflect, up to a certain extent, the DM's preferences, neuron inputs are weighted to represent the relative importance of each input to a processing element. Therefore, the ability to learn and generalize can be interesting in MCDA-based DSS, for instance, by using former decisions (in similar contexts) to tune a network of methods capable of replicating decisions (thus recognizing patterns of decisions) (Antunes \& Tsoukiàs 1997). 


\section{- Bayesian networks}

Bayesian networks provide a graphical representation of causality relationships between random variables using a directed acyclic graph, in which nodes represent variables and arcs represent the causality relationship between those variables. Each variable has a finite set of mutual exclusive states and a conditional probability table is assigned to each variable and its parents in the graph, thus leading to a joint probability distribution over the variables in the graph. Bayesian networks enable to integrate uncertainty in DSS, namely those based on expert knowledge and/or data measurements, in terms of probability of occurrence of an event knowing that some particular event occurred or to derive an a-priori unknown relationship between events through an inference and learning process. See (Jensen \& Nielsen 2010) for a full description.

Algorithms for computing posterior and predictive probabilities include belief propagation and junction trees, as well as statistical sampling techniques in large Bayesian networks. Influence diagrams may be viewed as an extension of Bayesian networks that can represent and solve decision problems under uncertainty by adding utility nodes (holding a table of utility values for all value configurations of the parent nodes) and decision nodes. They typically provide a more compact description than that provided by decision trees and are solved with a combination of probabilistic manipulations and dynamic programming. This allows performing decision related tasks, such as computing the expected utility and finding the optimal decision. Sometimes handling influence diagrams is too complex and we may need to use Monte Carlo simulation, possibly based on Markov chains (MCMC), see (Bielza et al. 1999).

About two-thirds of the papers included in this review use MCDA, optimization and rule-based approaches (see Figure 4). Figure 5 displays a trend revealing the growing importance of multicriteria approaches to capture not just the conflicting and incommensurate nature of the axes of evaluation of the merits of the courses of action but also to link this aspect to cope with uncertainty. It is also noticeable that Bayesian networks and fuzzy cognitive maps have not been much used in DSS until the more recent years, because efficient algorithms to perform the required computations were developed only lately. 


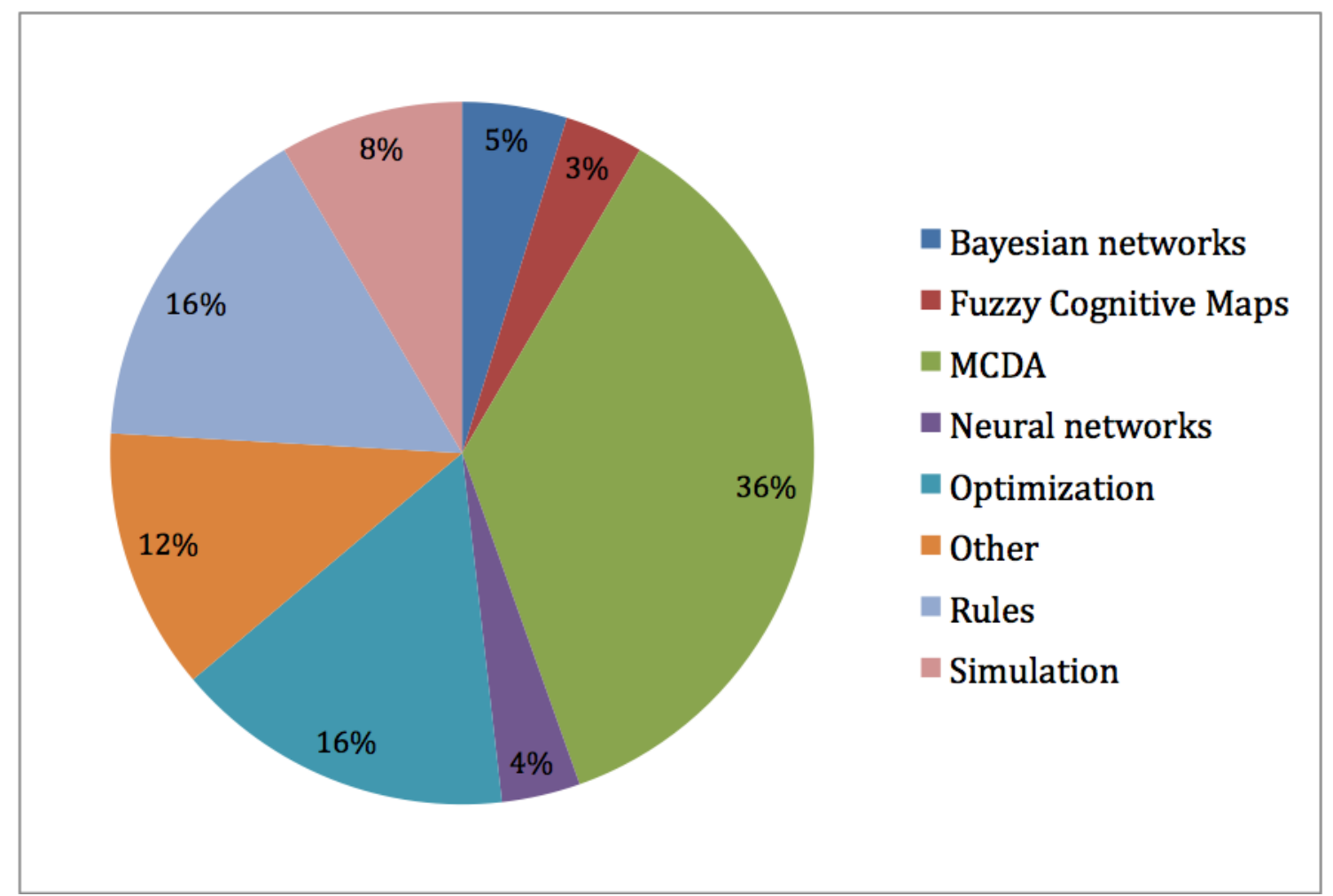

Figure 4. Frequency of underlying decision support methodology in this review.

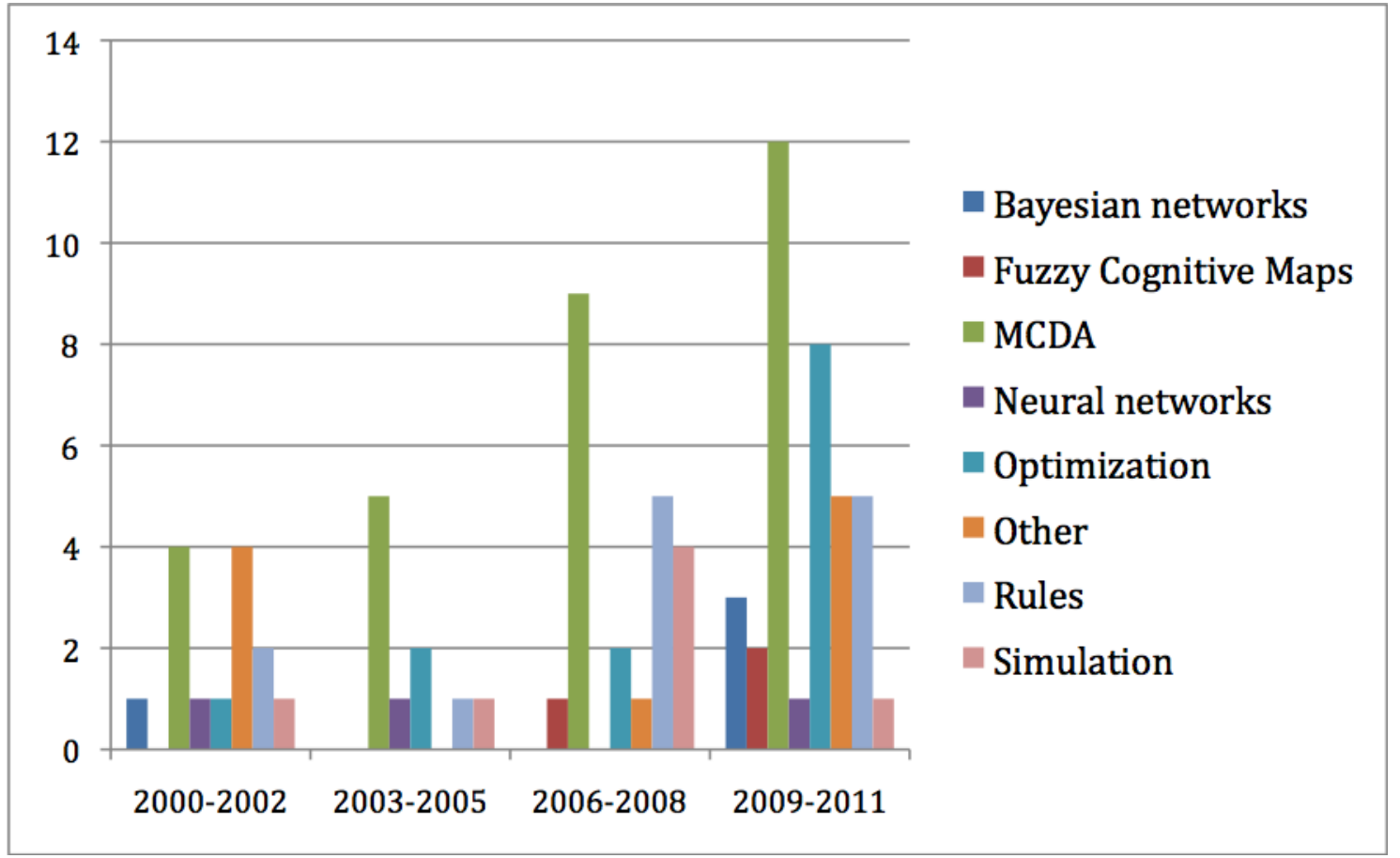

Figure 5. Evolution of underlying decision support methodology used. 


\section{DSS type}

As far as the DSS type is concerned, we consider the following categories: group-oriented, data-oriented, geography-oriented, knowledge-oriented, model-oriented, and web-oriented. Note that our categorization closely follows that of (Power 2004).

- Group-oriented

Group Decision Support Systems (GDSS) aim at improving the quality of decision processes whenever multiple DMs, often with conflicting goals, are involved generally in a (local or distant, synchronous or asynchronous) meeting environment. In these processes, in which negotiations and the establishment of compromises are required, GDSS should play a role in dealing with avoiding miscommunication, resolution of conflicts and generation of new ideas to overcome stalemates. The term Collaborative DSS also appears in the literature mostly referring to assist teams of DMs in the solution of ill-structured problems, in which emphasis is placed on mutual cooperation (rather than conflict resolution). According to the functionalities provided, this type of DSS may range from simple communication schemes to some form of more sophisticated collaborative computing, either using synchronous or asynchronous communications. Note that in this type of systems a key uncertainty source arises because of possible discrepancies among experts and/or stakeholders.

\section{- Data-oriented}

Data-oriented DSS emphasize access to and manipulation of large amounts of data, in general, historical data stored in data warehouse systems. The distinction between data-oriented and model-oriented DSS sometimes appears in the literature, although it is practically impossible to design data management procedures, especially for large collections of data, without also designing data-intensive analytical models and methods in an inter-dependent manner. In large companies and the public sector, the policy analysis and design processes largely rely on such data-oriented DSS, well beyond simple data-retrieval systems. Data oriented DSS are clearly plagued with uncertainty issues, for reasons outlined in our introduction.

\section{- Geography-oriented}

Spatial DSS are designed to assist users in decision-making processes involving spatial problems, such as the location of desirable, semi-desirable or obnoxious infrastructures. Modelling and analytical capabilities are coupled with geographic information systems (GIS) capabilities using a range of spatial (land use, water reservoirs, etc.) and non-spatial information (social or economic indicators, etc.) to analyse plausible scenarios and provide decision support in shaping decisions with spatial impact, such as the location of a new airport or routing the transportation of hazardous materials. In these problems multiple criteria evaluation of the merit of different alternatives (e.g., routes, areas) are generally at stake and must be explicitly taken into account in problem structuring, model building and analysis phases. For this type of DSS, built in procedures based on spatial statistics are clearly relevant for the type of uncertainty typically involved in spatial data, see e.g. (Ripley 2004).

- Knowledge-oriented

A knowledge-oriented DSS assists the decision making process using a knowledge base, which may be constructed according to different procedures of knowledge extraction, coupled with 
analytical methodologies. Since information resources on which knowledge is built are generally very heterogeneous, knowledge management should rely on specific formal languages through the entire life-cycle of knowledge generation, codification, sharing, and utilization. Ontologies (formal, explicit specifications of a shared conceptualization) are often used for knowledge representation in DSS because they facilitate the computational representation of background knowledge about complex domains. Due to the lack of ability of ontologies to deal explicitly with uncertainty, Bayesian networks have been proposed for probabilistic knowledge representation under uncertainty regarding both structure and numerical information, as described in Section 3.

- Model-oriented

According to (Power \& Sharda 2007), model-driven DSS are distinct from decision analysis or operations research computer-supported tools in making models accessible to non-technical users and being intended for frequent utilization in the same or similar decision situations. In model-oriented DSS, quantitative models are the core element of the DSS architecture and the level of functionality depends on the type of model - (multi-objective) optimization, (multicriteria) decision analysis, simulation, etc. Model-oriented DSS are not, in general, data intensive but they usually require sophisticated forms of preference information elicitation to be supplied in particular to multi-criteria decision analysis or multi-objective optimization models.

- Web-oriented

Web-based and web-enabled DSS are aimed at making the most of the web capabilities to facilitate decision support to managers, for instance to deal with group decision and negotiation problems in which the participants are geographically separated or in spatial planning problems using web GIS. Web-based DSS are implemented using web specific technologies having a web server as the central component. In web-enabled DSS some components are located in a remote legacy system and a browser can be used to access the full DSS functionalities. A present trend is DSS designed as stand-alone systems being migrated to web-enabled DSS adding the necessary web technology components, which involves lower costs and faster redevelopment processes than redesigning and implementing a full webbased system. This trend is witnessed, for instance, in moving mapping and GIS functionalities to the internet, thus profiting from the potential to make distributed geographic information and applications widely available using a browser. A popular strand in this respect is the new generation of e-participation systems that facilitate in various forms group decision support over the web, see (Rios Insua \& S. French 2010) for a description.

Model-oriented DSS are by far the most reported in this review, followed by knowledgeoriented DSS also displaying a growing trend (Figures 6 and 7). This trend recognizes the need to use well-structured decision models, and combine them with expert knowledge, to deal with several sources of uncertainty and reach robust conclusions. 


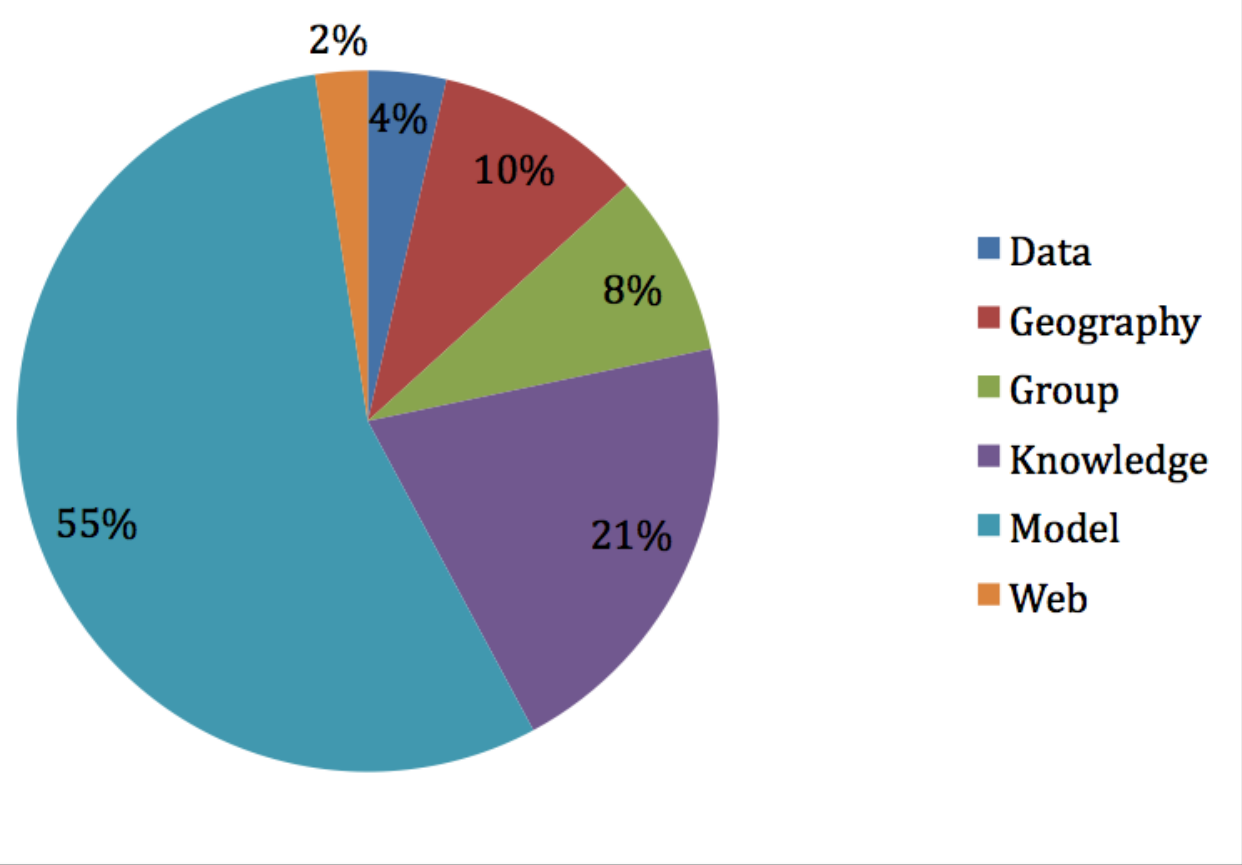

Figure 6. Frequency of different DSS types in this review.

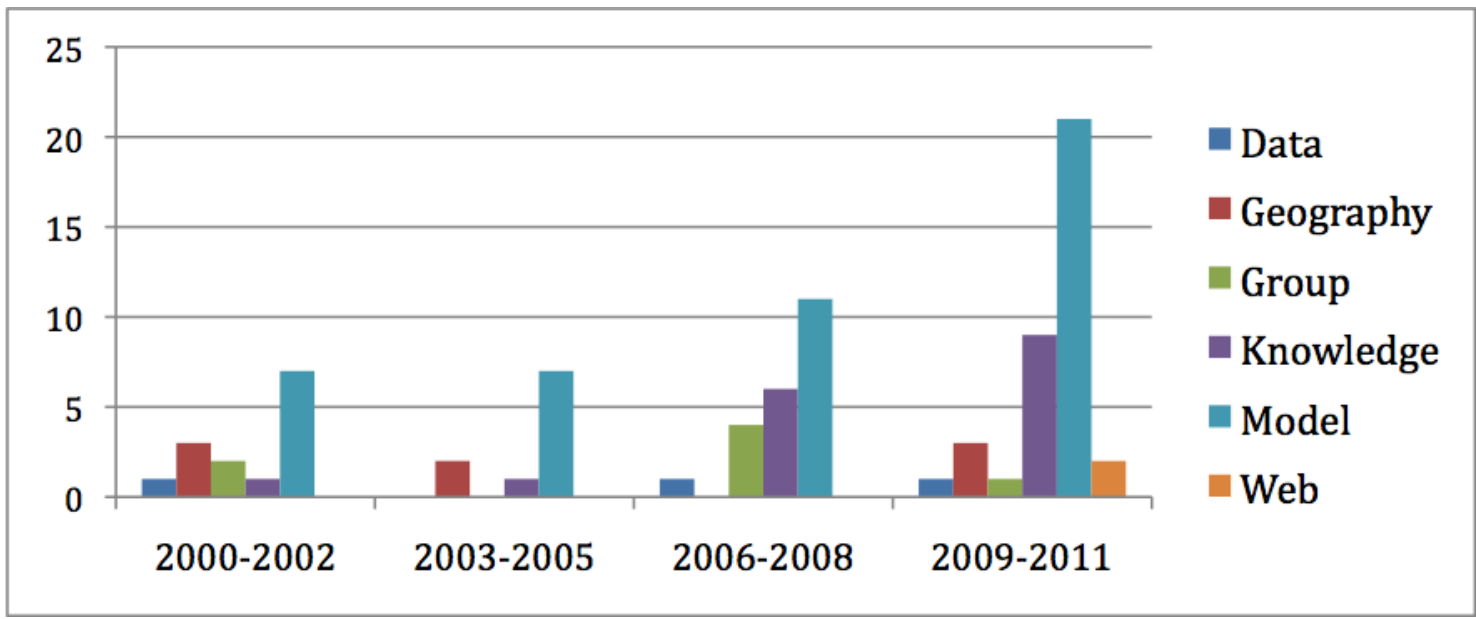

Figure 7. Evolution of DSS types used.

\section{Application areas}

The scope of applications that emerged in this review is quite diverse, suggesting the wide applicability of the methods, strategies and architectures proposed. The most represented application areas in this review are marketing/strategy, finance/economics, environment, water resources, medical, and operations management, which account for about threequarters of the applications reported in the literature reviewed (Figure 8). Somewhat more in detail, we may say that:

- Topics in marketing/strategy include marketing and strategy development, business process planning, fostering innovation, supplier selection, real state 
retailing and appraisal and negotiation. Typical uncertainties would include selling prices or degree of success of innovation initiatives.

- Topics in finance/economics include portfolio optimization, asset allocation, investment/project evaluation, cost estimation, price quoting, and insurance pricing. Typical sources of uncertainty would include market stability and asset prices.

- Topics in environmental management include restoration of contaminated ecosystems, land depletion assessment, assessment of regional climate change impacts, solid waste management, and life-cycle assessment of alternative technologies. Typical uncertainties would stem from changes in local weather patterns and evolution of contaminated ecosystems.

- Topics in water resources include ecological and hydrological processes, flood risk assessment and management, evaluation of drainage water tunnels, river basin planning and management, and water quality management. Typical uncertainties would include water demand for various purposes or water inflows at relevant points of the river basin.

- Topics in the medical area typically intend to model expert knowledge for medical diagnosis and prescription, with uncertainties in relation with the incumbent illnesses, their impact for instance in work productivity or retirement age, and the relevant risk factors.

- Topics in operations management include inventory management and control, scheduling, and maintenance, with uncertainties such as the product demand, availability of production machines, and cost estimates.

The evolution panorama (Figure 9) shows two noteworthy aspects: the range of application areas has been steadily growing, especially in connection with water resources management. 


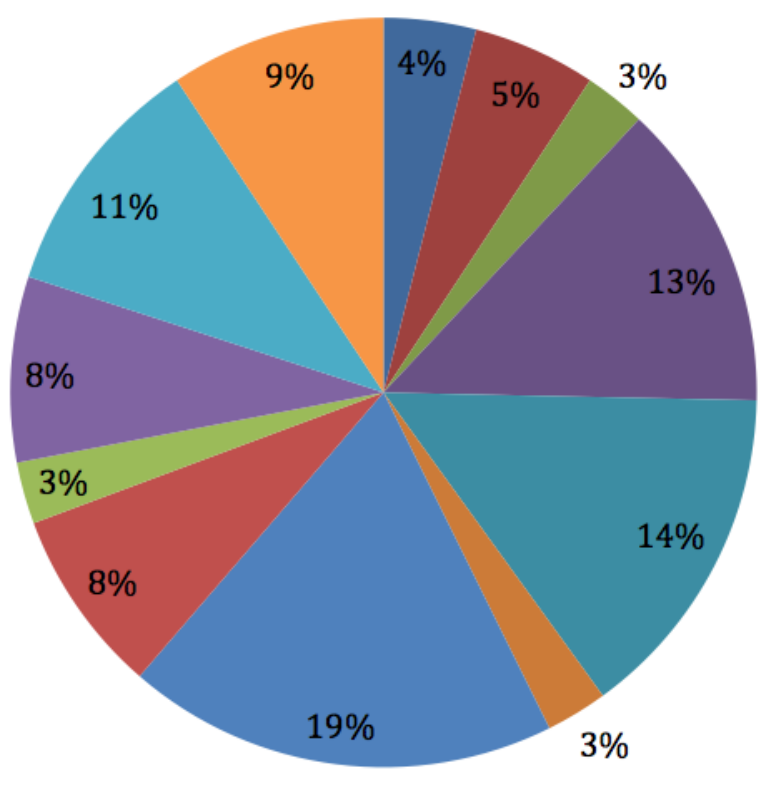

- Agriculture

Critical situations/risks

Energy

Environment

Finance/economics

Manufacturing

Marketing/strategy

Medical

Military

Operations management

Water resources

Other

Figure 8. Frequency of application areas in this review.

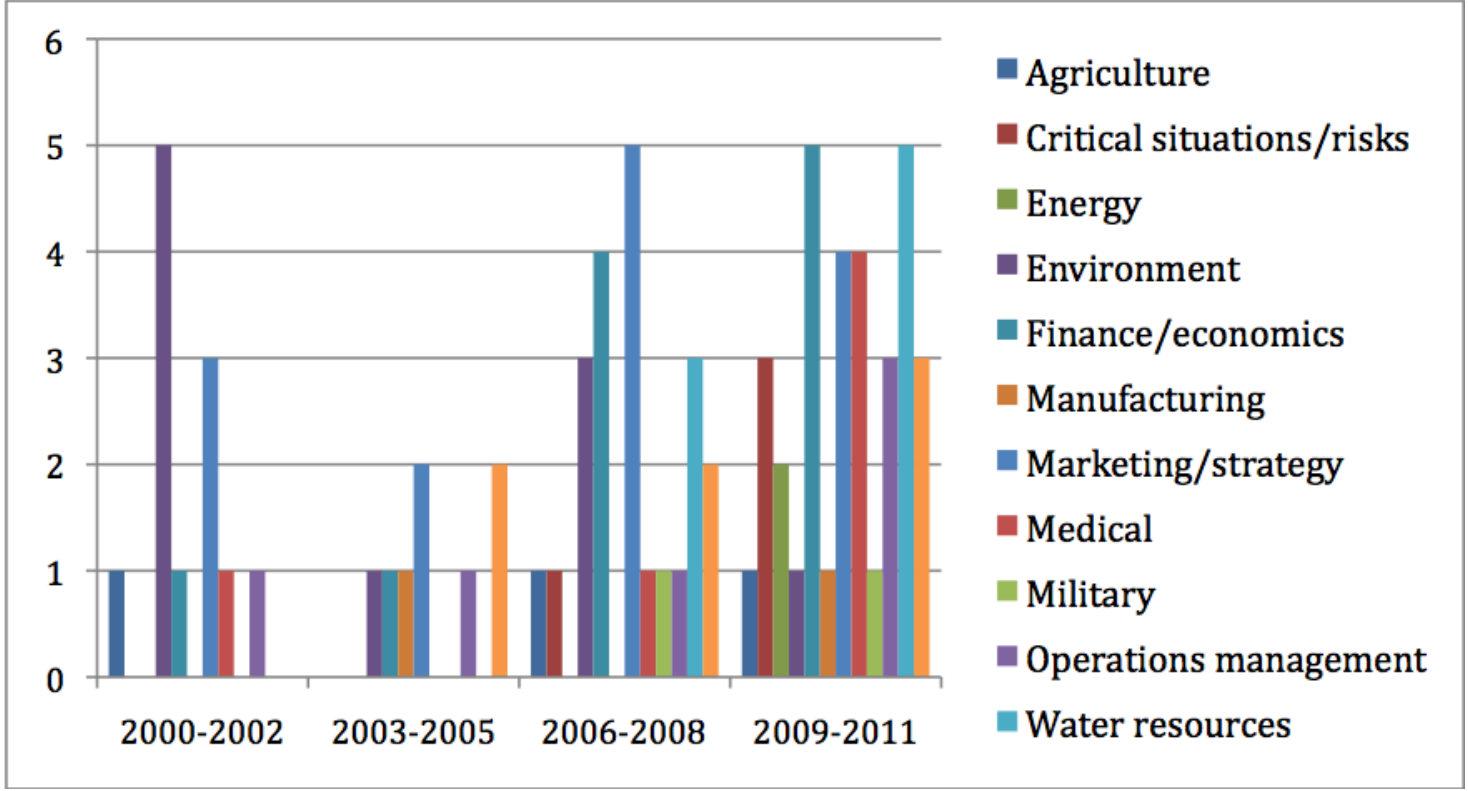

Figure 9. Evolution of application areas. 


\section{Conclusions}

We have provided an overview of how issues in relation with uncertainty, whatever its source might be, have been dealt within the applied DSS literature over the last twelve years. The variety of strategies to deal with uncertainties has increased in recent years. An interesting conclusion is that uncertainty is being increasingly addressed in decision support, with probabilistic models and fuzzy based approaches the most frequent strategies. Probabilistic models refer mainly to uncertainty issues, whereas fuzzy based models refer mainly to imprecision. When both issues arise, one is frequently led to one of the imprecise probability approaches, including possibility measures.

Although other frameworks such as Bayesian networks and fuzzy cognitive maps have been increasingly used in the more recent years, the underlying approaches for dealing with uncertainties are mostly MCDA, optimization and rule-based approaches, with a strong increasing tendency for MCDA. This brings the issue of dealing with uncertainty about preference-related parameters, which contributes to having ten cases in which a parametric analysis is performed. MCDA is also often associated with probabilistic modelling (ten cases) and fuzzy modelling (twelve cases).

In terms of DSS type, model-oriented DSS prevail, followed by knowledge-oriented DSS also displaying a growing trend. As expected, model-oriented DSS tend to be associated with MCDA or optimization approaches, whereas knowledge-oriented DSS tend to be associated with rules. Geography-oriented DSS are in a distant third position, with similar numbers of MCDA, optimization, and simulation approaches.

Concerning application areas, the areas of management prevail: applications on marketing/marketing plus economics/finance represent one third of the total. Next, one can identify a group of applications concerned with environmental sustainability: agriculture, energy, environment, and water resources account for approximately $30 \%$ of the applications.

Probabilistic and fuzzy strategies to deal with uncertainty are used in all fields. Fuzzy strategies are dominant in marketing, whereas probabilistic strategies seem to dominate in medical, environment and water resources applications (Table 3). Concerning the underlying approach (see Table 4), MCDA dominates in environment and water resources. In finance/economics MCDA and optimization share the protagonism. In marketing/strategy, MCDA and rule-based approaches prevail. Operations management is an area in which optimization is the most used.

\begin{tabular}{|c|c|c|c|c|c|c|c|}
\hline & $\begin{array}{l}\text { Evidential } \\
\text { Reasoning }\end{array}$ & Fuzzy & Interval & Parametric & $\begin{array}{l}\text { Possibility } \\
\text { theory }\end{array}$ & Probabilistic & Scenarios \\
\hline Agriculture & & 1 & & & & 2 & \\
\hline Critical situations/risks & & 3 & & & & 1 & \\
\hline Energy & & 1 & 1 & & & & 1 \\
\hline Environment & & 2 & & 3 & 1 & 5 & \\
\hline Finance/economics & 1 & 3 & & & 1 & 5 & 1 \\
\hline Manufacturing & & 1 & & & & & \\
\hline Marketing/strategy & 1 & 8 & & 3 & & 3 & \\
\hline Medical & 1 & 1 & & & & 4 & \\
\hline Military & & 1 & & & & 2 & \\
\hline Operations mgt. & & 1 & & 2 & & 3 & \\
\hline
\end{tabular}


Table 3. Application vs Strategy to deal with uncertainty.

\begin{tabular}{|c|c|c|c|c|c|c|c|}
\hline & $\begin{array}{l}\text { Bayesian } \\
\text { networks }\end{array}$ & FCMs & MCDA & $\begin{array}{l}\text { Neural } \\
\text { networks }\end{array}$ & Optimization & Rules & Simulation \\
\hline Agriculture & 1 & & & & & 1 & 1 \\
\hline Critical situations/risks & & 1 & 1 & & 1 & & 1 \\
\hline Energy & & & 1 & & 1 & & \\
\hline Environment & & & 6 & & & 1 & \\
\hline Finance/economics & & & 4 & & 4 & 2 & 1 \\
\hline Manufacturing & & & & 1 & & & \\
\hline Marketing/strategy & & 1 & 6 & 1 & 1 & 5 & \\
\hline Medical & & 1 & & 1 & & 3 & 1 \\
\hline Military & 1 & & 1 & & & & \\
\hline Operations mgt. & & & 1 & & 4 & & \\
\hline Water resources & & & 4 & & 1 & & 2 \\
\hline
\end{tabular}

Table 4. Application vs Underlying approach

We may, therefore, conclude that uncertainty is of growing concern in actual decision support systems, as indeed should be, with an increasing number of DSS addressing issues in connection with uncertainty in many application domains. Given this vitality, which is witnessed in this review, some issues could be discussed as outlined below.

Most of the DSSs reviewed are ad-hoc in the sense that they are developed with a specific application in mind. It seems there is ground for the development of generic DSSs based on given methodologies. Some generic systems include WINBUGS, implementing Markov chain Monte Carlo methods in graphical models, or GeNle to evaluate influence diagrams.

A methodological area of outmost importance for applications is the elicitation of judgments, both as far probabilities and other paradigms are concerned. Much remains to be done in the art and science of elicitation procedures. In this respect, an important problem refers to multiple experts and multiple models, one example being uncertainty in climate change. In this area, there are numerous competing models, most of them predicting global warming, differing, however, in the estimates of the extent of such effect and the uncertainty around it. We may deal with such issue through model averaging; however, most approaches assume independence among models and expert judgments, typically leading to less uncertainty than should be acknowledged.

The example of climate change also points out to another emerging area, that of severe uncertainty, which frames much of long-term policy making. This is frequently undertaken via scenario analysis and there is an increasing interest in combining this approach with MCDA methods. 
Solving these, and other important challenges, will no doubt help in promoting even more the incorporation of uncertainty models into actual decision aiding and decision support systems. While writing this review, much of Europe is drowning on economic uncertainty amid discussions by politicians attempting to steer a continent with their actions (and inactions). We do not anticipate any shortage of opportunities to use uncertainty modelling methods and software.

\section{Acknowledgements}

L. Dias and C. H. Antunes would like to thank FCT (Portuguese Foundation for Science and Technology) for support under Project PEst-C/EEI/UI0308/2011. The work of DRI is supported by grants from the Spanish Government (RIESGOS, CORPORATE COMMUNITY, DEMOCRACY4ALL) and the Government of Madrid (RIESGOS-CM). We are all grateful to the ESF COST Action in Algorithmic Decision Theory.

\section{References}

Ades, A.E. \& Cliffe, S., 2002. Markov Chain Monte Carlo Estimation of a Multiparameter Decision Model: Consistency of Evidence and the Accurate Assessment of Uncertainty. Medical Decision Making, 22(4), pp.359-371.

Aerts, J.C.J.H., Goodchild, M.F. \& Heuvelink, G.B.M., 2003. Accounting for Spatial Uncertainty in Optimization with Spatial Decision Support Systems. Transactions in GIS, 7(2), pp.211230.

Antunes, C.H. \& Tsoukiàs, A., 1997. Against fashion: a travel survival kit in modern MCDA. In J. Clímaco, ed. Multicriteria Analysis - Proceedings of the XI International Conference on Multiple Criteria Decision Making. Springer-Verlag, pp. 378-389.

Augusto, J.C. et al., 2008. Management of Uncertainty and Spatio-Temporal Aspects for Monitoring and Diagnosis in a Smart Home. International Journal of Computational Intelligence Systems, 1(4), p.361.

Beraldi, P., Violi, A. \& De Simone, F., 2011. A decision support system for strategic asset allocation. Decision Support Systems, 51(3), pp.549-561.

Besharati, B., Azarm, S. \& Kannan, P.K., 2006. A decision support system for product design selection: A generalized purchase modeling approach. Decision Support Systems, 42(1), pp.333-350.

Beynon, M., Cosker, D. \& Marshall, D., 2001. An expert system for multi-criteria decision making using Dempster Shafer theory. Expert Systems with Applications, 20(4), pp.357367.

Bielza, C., Mueller, P. \& Insua, D.R., 1999. Decision Analysis by Augmented Probability Simulation. Management Science, 45(7), pp.995-1007. 
Birge, J. \& Louveaux, F., 2011. Introduction to Stochastic Programming, Springer.

Borges, A.R. \& Antunes, Carlos Henggeler, 2003. A weight space-based approach to fuzzy multiple-objective linear programming. Decision Support Systems, 34(4), pp.427-443.

Burstein, F. \& Holsapple, C.W., 2008. Handbook on Decision Support Systems (vols 1\&2), Springer.

Cai, Y.P. et al., 2009. An optimization-model-based interactive decision support system for regional energy management systems planning under uncertainty. Expert Systems with Applications, 36(2), pp.3470-3482.

Castelletti, A., Pianosi, F. \& Soncini-Sessa, R., 2008. Integration, participation and optimal control in water resources planning and management. Applied Mathematics and Computation, 206(1), pp.21-33.

Chen, H. et al., 2011. Uncertainty analysis in a GIS-based multi-criteria analysis tool for river catchment management. Environmental Modelling \& Software, 26(4), pp.395-405.

Chin, K.-S. et al., 2008. Group-based ER-AHP system for product project screening. Expert Systems with Applications, 35(4), pp.1909-1929.

Chou, J.-S., 2009. Generalized linear model-based expert system for estimating the cost of transportation projects. Expert Systems with Applications, 36(3), pp.4253-4267.

Clímaco, João N. et al., 2009. Supporting Collaborative Multi-Criteria Evaluation. International Journal of Decision Support System Technology, 1(4), pp.1-15.

Contesse, L., Ferrer, J.C. \& Maturana, S., 2005. A Mixed-Integer Programming Model for Gas Purchase and Transportation. Annals of Operations Research, 139(1), pp.39-63.

Damghani, K.K., Sadi-Nezhad, S. \& Aryanezhad, M.B., 2011. A modular Decision Support System for optimum investment selection in presence of uncertainty: Combination of fuzzy mathematical programming and fuzzy rule based system. Expert Systems with Applications, 38(1), pp.824-834.

Dias, L. \& Clímaco, J.N., 2000. Additive aggregation with variable interdependent parameters: The VIP analysis software. Journal of the Operational Research Society, 51(9), pp.10701082.

Dias, L.C. \& Mousseau, V., 2003. IRIS: a DSS for multiple criteria sorting problems. Journal of Multi-Criteria Decision Analysis, 12(4-5), pp.285-298.

Disney, SM, Naim, M. \& Towill, D., 2000. Genetic algorithm optimisation of a class of inventory control systems. International Journal of Production Economics, 68(3), pp.259-278.

French, S., 1986. Decision Theory, Ellis Horwood.

French, Simon, Maule, J. \& Papamichail, N., 2009. Decision behaviour, analysis and support, Cambridge University Press. 
French, S. \& Rios Insua, D., 2000. Statistical Decision Theory E. Arnold, ed.,

Gascón, F. et al., 2007. On macroeconomic characteristics of pharmaceutical generics and the potential for manufacturing and consumption under fuzzy conditions. Artificial intelligence in medicine, 41(3), pp.223-35.

Gemici-Ozkan, B. et al., 2010. R\&D Project Portfolio Analysis for the Semiconductor Industry. Operations Research, 58(6), pp.1548-1563.

Gendreau, M. \& Potvin, J.-Y. (eds), 2010. Handbook of Metaheuristics, Springer.

Gigerenzer, G., Todd, P.M., \& the A.R.G., 1999. Simple Heuristics that make us smart, Oxford University Press.

Gijsman, A.J., Thornton, P.K. \& Hoogenboom, G., 2007. Using the WISE database to parameterize soil inputs for crop simulation models. Computers and Electronics in Agriculture, 56(2), pp.85-100.

Glykas, M. (ed), 2010. Fuzzy Cognitive Maps: Advances in Theories, Methodologies, Applications and Tools, Springer.

Gomes, C. et al., 2008. Multicriteria decision making applied to waste recycling in Brazil. Omega, 36(3), pp.395-404.

Guezguez, W., Ben Amor, N. \& Mellouli, K., 2009. Qualitative possibilistic influence diagrams based on qualitative possibilistic utilities. European Journal of Operational Research, 195(1), pp.223-238.

Guitouni, A. et al., 2008. Multiple Criteria Courses of Action Selection. Military Operations Research, 13(1), pp.35-50.

He, L. et al., 2006. A probabilistic reasoning-based decision support system for selection of remediation technologies for petroleum-contaminated sites. Expert Systems with Applications, 30(4), pp.783-795.

Jensen, F. \& Nielsen, T., 2010. Bayesian Networks and Decision Graphs, Springer.

Jiménez, A. et al., 2007. Contracting cleaning services in a European public underground transportation company with the aid of a DSS. Decision Support Systems, 43(4), pp.14851498.

Jiménez, A., Mateos, Alfonso \& Ríos-Insua, Sixto, 2009. Missing consequences in multiattribute utility theory. Omega, 37(2), pp.395-410.

Jiménez, A., Ríos-Insua, Sixto \& Mateos, Alfonso, 2006. A generic multi-attribute analysis system. Computers \& Operations Research, 33(4), pp.1081-1101.

Jiménez, A., Ríos-Insua, S. \& Mateos, Alfonso, 2003. A decision support system for multiattribute utility evaluation based on imprecise assignments. Decision Support Systems, 36(1), pp.65-79. 
Kala, R., Shukla, A. \& Tiwari, R., 2011. Modular symbiotic adaptive neuro evolution for high dimensionality classificatory problems. Intelligent Decision Technologies, 5(4), pp.309319.

Karacapilidis, N. \& Pappis, C., 2000. Computer-supported collaborative argumentation and fuzzy similarity measures in multiple criteria decision making. Computers \& Operations Research, 27(7-8), pp.653-671.

Kirkwood, C.W., Slaven, M.P. \& Maltz, A., 2005. Improving Supply-Chain-Reconfiguration Decisions at IBM. Interfaces, 35(6), pp.460-473.

Kong, G. et al., 2009. Applying a belief rule-base inference methodology to a guideline-based clinical decision support system. Expert Systems, 26(5), pp.391-408.

de Kort, I.A.T. \& Booij, M.J., 2007. Decision making under uncertainty in a decision support system for the Red River. Environmental Modelling \& Software, 22(2), pp.128-136.

Kosko, B., 1992. Neural networks and fuzzy systems, Prentice-Hall.

Kouvelis, P. \& Yu, G., 1987. Robust Discrete Optimization, Springer.

Kristensen, K. \& Rasmussen, I.A., 2002. The use of a Bayesian network in the design of a decision support system for growing malting barley without use of pesticides. Computers and Electronics in Agriculture, 33(3), pp.197-217.

Könnölä, T., Brummer, V. \& Salo, Ahti, 2007. Diversity in foresight: Insights from the fostering of innovation ideas. Technological Forecasting and Social Change, 74(5), pp.608-626.

Lee, K. \& Kwon, S., 2008. CAKES-NEGO: Causal knowledge-based expert system for B2B negotiation. Expert Systems with Applications, 35(1-2), pp.459-471.

Leu, S.-S. \& Adi, T.J.W., 2011. Microtunneling decision support system (MDS) using NeuralAutoregressive Hidden Markov Model. Expert Systems with Applications, 38(5), pp.58015808.

Li, L., Wang, J. \& Wang, C., 2005. Typhoon insurance pricing with spatial decision support tools. International Journal of Geographical Information Science, 19(3), pp.363-384.

Li, S., 2000. The development of a hybrid intelligent system for developing marketing strategy. Decision Support Systems, 27(4), pp.395-409.

Li, S. et al., 2011. WebDigital: A Web-based hybrid intelligent knowledge automation system for developing digital marketing strategies. Expert Systems with Applications, 38(8), pp.10606-10613.

Li, S. \& Li, J.Z., 2009. Hybridising human judgment, AHP, simulation and a fuzzy expert system for strategy formulation under uncertainty. Expert Systems with Applications, 36(3), pp.5557-5564. 
Lin, L., Hu, P.J.-H. \& Liu Sheng, O.R., 2006. A decision support system for lower back pain diagnosis: Uncertainty management and clinical evaluations. Decision Support Systems, 42(2), pp.1152-1169.

Loboda, T.D.., Brusilovsky, P. \& Grady, J., 2010. An agent for versatile intelligence analysis system. Intelligent Decision Technologies, 4(2), pp.133-148.

Lou, H.H. \& Huang, Y.L., 2003. Hierarchical decision making for proactive quality control: system development for defect reduction in automotive coating operations. Engineering Applications of Artificial Intelligence, 16(3), pp.237-250.

Lourenço, R.P. \& Costa, J.P., 2007. Incorporating citizens' views in local policy decision making processes. Decision Support Systems, 43(4), pp.1499-1511.

Louvieris, P., Gregoriades, A. \& Garn, W., 2010. Assessing critical success factors for military decision support. Expert Systems with Applications, 37(12), pp.8229-8241.

Lu, J., Zhang, G. \& Wu, F., 2008. Team Situation Awareness Using Web-based Fuzzy Group Decision Support Systems. International Journal of Computational Intelligence Systems, $1(1)$, p.50.

Ma, J., Lu, J. \& Zhang, G., 2010. Decider: A fuzzy multi-criteria group decision support system. Knowledge-Based Systems, 23(1), pp.23-31.

Mackay, D.S. \& Robinson, V.B., 2000. A multiple criteria decision support system for testing integrated environmental models. Fuzzy Sets and Systems, 113(1), pp.53-67.

De Maio, C. et al., 2011. A knowledge-based framework for emergency DSS. Knowledge-Based Systems, 24(8), pp.1372-1379.

Mateos, A., Ríos-Insua, S. \& Gallego, E., 2001. Postoptimal analysis in a multi-attribute decision model for restoring contaminated aquatic ecosystems. Journal of the Operational Research Society, 52(7), pp.727-738.

Miranda, E., 2008. A survey of the theory of coherent lower previsions. International Journal of Approximate Reasoning, 48(2), pp.628-658.

Montmain, J., Sanchez, C. \& Vinches, M., 2009. Multi criteria analyses for managing motorway company facilities: The decision support system SINERGIE. Advanced Engineering Informatics, 23(3), pp.265-287.

Morgan, M.G. \& Henrion, M., 1990. Uncertainty: a guide to the treatment of uncertainty in quantitative policy and risk analysis, Cambridge University Press NY.

Mouzakitis, S. et al., 2011. A Fuzzy Multi-Criteria Outranking Approach in Support of Business Angels' Decision Analysis Process for the Assessment of Companies as Investment Opportunities. Journal of Optimization Theory and Applications, 150(1), pp.156-165.

Namen, A.A., Bornstein, C.T. \& Rosenhead, J., 2008. Robustness analysis for sustainable community development. Journal of the Operational Research Society, 60(5), pp.587-597. 
Noor-E-Alam, M. et al., 2011. Algorithms for fuzzy multi expert multi criteria decision making (ME-MCDM). Knowledge-Based Systems, 24(3), pp.367-377.

Olson, D.L. et al., 2007. Capturing the high-risk environment of the transition economy in Bulgaria-a simulation-based DSS. Decision Support Systems, 42(4), pp.2004-2015.

O’Hagan, A. et al., 2006. Uncertain Judgements: Eliciting Experts' Probabilities, Wiley.

Packham, I.S.J. et al., 2005. Interactive visualisation for decision support and evaluation of robustness-in theory and in practice. Advanced Engineering Informatics, 19(4), pp.263280.

Papadopoulos, A., Kalivas, D. \& Hatzichristos, T., 2011. Decision support system for nitrogen fertilization using fuzzy theory. Computers and Electronics in Agriculture, 78(2), pp.130139.

Papageorgiou, E.I., 2011. A Fuzzy Inference Map approach to cope with uncertainty in modeling medical knowledge and making decisions. Intelligent Decision Technologies, 5(3), pp.219-235.

Patiniotakis, I., Apostolou, D. \& Mentzas, G., 2011. Fuzzy UTASTAR: A method for discovering utility functions from fuzzy data. Expert Systems with Applications, 38(12), pp.1546315474.

Pereira, L.M. \& Ramli, C.K., 2010. Modelling decision making with probabilistic causation. Intelligent Decision Technologies, 4(2), pp.133-148.

Power, D.J., 2004. Specifying An Expanded Framework for Classifying and Describing Decision Support Systems. Communications of the Association for Information Systems, 13(13), pp.158-166.

Power, D.J. \& Sharda, R., 2007. Model-driven decision support systems: Concepts and research directions. Decision Support Systems, 43(3), pp.1044-1061.

Qi, H. \& Altinakar, M.S., 2011. A GIS-based decision support system for integrated flood management under uncertainty with two dimensional numerical simulations. Environmental Modelling \& Software, 26(6), pp.817-821.

Rees, L.P. et al., 2011. Decision support for Cybersecurity risk planning. Decision Support Systems, 51(3), pp.493-505.

Rios Insua, D. \& French, S., 2010. eParticipation: A Group Decision and Negotiation Approach, Springer.

Rios Insua, D. \& Ruggeri, F., 2000. Robust Bayesian Analysis, Yew York: Springer.

Ripley, B., 2004. Spatial Statistics, Wiley.

Ross, T., 2010. Fuzzy Logic with Engineering Applications, Wiley. 
Ríos Insua, D. et al., 2000. MOIRA: A decision support system for decision making on aquatic ecosystems contaminated by radioactive fallout. Annals of Operations Research, 95(1-4), pp.341-364.

Saenz de Ugarte, B. et al., 2009. Development and integration of a reactive real-time decision support system in the aluminum industry. Engineering Applications of Artificial Intelligence, 22(6), pp.897-905.

Salling, K.B., Leleur, S. \& Jensen, A.V., 2007. Modelling decision support and uncertainty for large transport infrastructure projects: The CLG-DSS model of the Øresund Fixed Link. Decision Support Systems, 43(4), pp.1539-1547.

Schoemaker, P.J.H. \& Waid, C.C., 1982. An Experimental Comparison of Different Approaches to Determining Weights in Additive Utility Models. Management Science, 28(2), pp.182196.

Shafer, G., 1976. A Mathematical Theory of Evidence, Princeton University Press.

Tan, R.R., Culaba, A.B. \& Purvis, M.R.., 2004. POLCAGE 1.0-a possibilistic life-cycle assessment model for evaluating alternative transportation fuels. Environmental Modelling \& Software, 19(10), pp.907-918.

Tarantola, S. et al., 2002. Can global sensitivity analysis steer the implementation of models for environmental assessments and decision-making? Stochastic Environmental Research and Risk Assessment (SERRA), 16(1), pp.63-76.

Ting, S.L. et al., 2011. A hybrid knowledge-based approach to supporting the medical prescription for general practitioners: Real case in a Hong Kong medical center. Knowledge-Based Systems, 24(3), pp.444-456.

Vilkkumaa, E., Salo, A. \& Liesiö, J., Multicriteria Portfolio Modeling for the Development of Shared Action Agendas. Group Decision and Negotiation.

Völkner, P. \& Werners, B., 2002. A simulation-based decision support system for business process planning. Fuzzy Sets and Systems, 125(3), pp.275-287.

Wang, C.-N. et al., 2011. Evaluating the manufacturing capability of a lithographic area by using a novel vague GERT. Expert Systems with Applications, 38(1), pp.923-932.

Weng, S.Q., Huang, G.H. \& Li, Y.P., 2010. An integrated scenario-based multi-criteria decision support system for water resources management and planning - A case study in the Haihe River Basin. Expert Systems with Applications, 37(12), pp.8242-8254.

Wilby, R.., Dawson, C.. \& Barrow, E.., 2002. sdsm - a decision support tool for the assessment of regional climate change impacts. Environmental Modelling \& Software, 17(2), pp.145157.

Wright, G. \& Goodwin, P., 1999. Future-focussed thinking: combining scenario planning with decision analysis. Journal of Multi-Criteria Decision Analysis, 8(6), pp.311-321. 
Xu, D.-L., Yang, Jian-Bo \& Wang, Y.-M., 2006. The evidential reasoning approach for multiattribute decision analysis under interval uncertainty. European Journal of Operational Research, 174(3), pp.1914-1943.

Xu, Y.-P., Booij, M.J. \& Mynett, A.E., 2007. An appropriateness framework for the Dutch Meuse decision support system. Environmental Modelling \& Software, 22(11), pp.1667-1678.

Yang, J-B et al., 2010. Multicriteria evidential reasoning decision modelling and analysisprioritizing voices of customer. Journal of the Operational Research Society, 62(9), pp.1638-1654.

Yazgı Tütüncü, G. et al., 2008. Continuous review inventory control in the presence of fuzzy costs. International Journal of Production Economics, 113(2), pp.775-784.

Zack, M.H., 2007. The role of decision support systems in an indeterminate world. Decision Support Systems, 43(4), pp.1664-1674.

Zadeh, L.A., 1978. Fuzzy sets as a basis for a theory of possibility. Fuzzy Sets and Systems, 1, pp.3-28.

Zeng, T.Q. \& Zhou, Q., 2001. Optimal spatial decision making using GIS: a prototype of a real estate geographical information system (REGIS). International Journal of Geographical Information Science, 15(4), pp.307-321.

Zhang, T. et al., 2010. Power distribution system planning evaluation by a fuzzy multi-criteria group decision support system. International Journal of Computational Intelligence Systems, 3(4), pp.474-485.

Zhang, X. et al., 2011. Model-based decision support system for water quality management under hybrid uncertainty. Expert Systems with Applications, 38(3), pp.2809-2816.

Zhou, L., Disney, Stephen \& Towill, D.R., 2010. A pragmatic approach to the design of bullwhip controllers. International Journal of Production Economics, 128(2), pp.556-568. 